Journal of Education and Educational Development

8(2), 359-378, 2021

DOI: http://dx.doi.org/10.22555/joeed.v8i2.481

\title{
The Effect of Mushroom Manager Behavior on Organizational Charlatan and Organizational Loneliness
}

\author{
Hüsnü Ergun \\ Ministry of National Education, Turkey
}

\begin{abstract}
This study aims to examine the prediction of the mushroom-type management approach on the loneliness levels of the employees and organizational charlatan behaviors in schools. There is no study investigating the relationship between these variables and studies examining the relationship of these variables with other variables are limited. Thus, this study aimed to fill the gap in the literature. The research was designed in a relational screening model and was carried out in the province of Denizli in Turkey with 464 participants. In the research, the mushroom type management scale, UCLA loneliness scale-3, and organizational charlatan scale were used. Validity and reliability studies of the mushroom-type management scale for schools were reconstructed. UCLA loneliness scale-3 and organizational charlatan scales were adapted to Turkish by the researcher. Data were collected with the help of electronic forms. Regression analysis was carried out to determine the extent to which mushroom type management predicted teachers'organizational loneliness behaviors and teachers' organizational charlatan behaviors. Results demonstrated that mushroom management positively affects the two variables; therefore, school principals should avoid mushroom-type management behavior in order not to push his/her teacher towards charlatanism or loneliness.
\end{abstract}

Keywords: charlatan, loneliness, mushroom management, school principal

\section{Introduction}

Organizations perform certain tasks with the help of their members in cooperation and coordination. Schools, like all other organizations, carry out their education and training with the help of teachers and other employees. While a teacher tries to improve the students in his class, he will not be able to accomplish 
this goal without the help of other employees of the school. Likewise, the policies to be applied to the student's extracurricular cannot be independent of each other. All these jobs are managed under the leadership of the school principal. The school principal may feel the need to be distinguished from the staff and therefore may not want to talk to the teachers about the policies to be implemented or the real purpose of the job.

The principal tries to guide the teacher with different instructions. The school principal can conduct some work in confidentiality to which school workers may not agree to as they anticipate transparency from their school principal (Ergün, 2020c). This research examined the effect of mushroom-type management, namely the behavior of the manager, who try to direct the teachers without informing them (Kılıç \& Olgun, 2017; Tekin \& Birincioğlu, 2017), in terms of organizational loneliness and organizational charlatanism. The mushroom type management pushes subordinates to either be a charlatan, who pretends to have a good performance among others and try falsely to be evaluated well by others (Abraham \& Berline, 2015), or loneliness which is a cause of unrest in a person (Demirbaş \& Haşit, 2016).

This study aims to examine the prediction of the mushroom-type management approach on the loneliness levels of the employees and organizational charlatan behaviors. Therefore, this study aimed to fill the gap in the literature in two ways. First to identify the prediction of mushroom type management on loneliness and charlatanism, where there are limited findings on this relationship in existing theory. Second, this study has been conducted among school teachers in the province of Denizli Turkey, where there are no current findings related to this sample. Mushroom-type management behavior can cause employees to show themselves better than they are or become introverted. The research tests the hypotheses that Mushroom-type management behavior predicts teachers' organizational loneliness and organizational charlatanism. While examining whether mushroom management predicts organizational loneliness, it will be necessary to look at the dimensions of organizational loneliness separately. Thus, it will be found out which dimension is predicted by fungal type management at what level. Therefore, drawing from these gaps, this paper raises two questions; 
1. Does mushroom-type management behavior predict teachers' organizational loneliness?

2. Does mushroom-type management behavior predict teachers' organizational charlatan behaviors?

\section{Literature Review}

\section{Mushroom Type Manager}

The mushroom-type manager does not make any statements to his/ her subordinates but this type of manager tries to direct the employees through instructions. The name mushroom-type managers were given to them by Tekin and Birincioğlu (2017) because like the mushrooms that are left in the dark and only fertilizer is given to them; employees are also deliberately left in the dark without any explanation and only instructions are given to them. Mushroom-type managers hide information from their subordinates and although this is perceived as a negative behavior, it can become a useful tool for managers in such situations as preventing chaos and protecting the privacy of the organization (Kılıç \& Olgun, 2017). In this approach, the managers are protected from the inquiries and criticisms of the employees, keeping the power and knowledge to themselves (Tekin \& Birincioğlu, 2017). Thus, the mushroom management style implies that the decisions are made by managers, and information is not shared with employees (Birincioğlu \& Tekin, 2018).

While the mushroom-type manager is reluctant to share information and participant management, this creates information asymmetry and a lack of communication (Birincioğlu \& Tekin, 2018). Managers with a mushroom management style do not want to explain the reason for their work to the employees. In a sense, they may want to be protected from the queries and criticisms of the employees by gathering power and information (Birincioğlu \& Tekin, 2018).

Previous researchers have proved, it is possible to find mushroom management style in the health sector or universities; it was found that this situation negatively affected employees' performance, motivation levels, and commitment. (Kılıç, 2015; Tekin \& Birincioğlu, 2017). In the mushroom management approach, employees' intention to leave the organization, their insecurity towards their organizations may increase and situations of power poisoning may arise in 
management (Tekin \& Birincioğlu, 2017). Employees who prefer the participatory management approach want to participate in the decision-making process even if the performance of the organization deteriorates (Kahya \& Ceylan, 2019).

Organizations may attach importance to a participatory and transparent understanding, so that they may measure the process and share the results of the measurement with the employees to get away from the mushroom management approach. They can also increase employee engagement and productivity by holding monthly one-on-one meetings, weekly news bulletins, real-time progress updates, and quarterly meetings with all employees. When these happen, employees will not feel like mushrooms (Kahya \& Ceylan, 2019; Miller, 2016). The school principal has to abandon the mushroom-type management behavior, otherwise, employees may choose loneliness or charlatan behaviors to protect themselves from this dark environment.

\section{Loneliness}

Human beings are social by nature; therefore, people need other people to talk to and share their feelings with. In a school setting also, employees communicate with other and share both, their private and work life and seek solutions to their problems as well as share their experiences. But at times, people either want to be left alone or want to move away from a specific environment or persons (Ergün, 2020).

Loneliness is a psychological condition (Demirbaş \& Haşit, 2016) which is defined in the dictionary of the Turkish Language Institute (2014) as the state of being alone, desolate, and a person who is not accompanied by anyone and lacks social relations. The lonely person lives alone, establishing an average of less than one monthly relationship with relatives and friends. Loneliness is to be alone; however, this condition may cause a person can stay alone even in a crowd (Yaşar, 2007).

A lot of research has been done on loneliness. There are research results that conclude that loneliness leads to depression or vice versa and that loneliness can also result in eating disorders (Y1ldirım et al., 2018). The feeling of loneliness among the managers changes according to the cultures they live in (Y1lmaz \& Altınok, 2009); whereas, the loneliness of students varies. The level of loneliness 
of students whose parents are university graduates is lower, those who have more siblings are lonelier and the ones with high income are less alone (Duyan et al., 2008). Gender and socioeconomic class have no significant effect on explaining loneliness (Özdemir \& İlhan, 2012) whereas internet use and loneliness trigger each other (Özen, 2009). Perceived organizational support does not affect academicians' loneliness in business life (Çetin \& Alacalar, 2016). It was also noted that the nature of the job affects one's loneliness such that education inspectors are left alone due to the nature of the inspection within the unit, and due to the changes in legal arrangements in inter-unit relations (Kayıkçı \& Özyıldırım, 2019). One's desire to reach the top position brings the risk of loneliness (Rokach, 2014). Consequently, loneliness at work positively affects the intention to quit (Demirbaş \& Haşit, 2016). Among the studies carried on loneliness, no studies have been found investigating the relationship of loneliness with the mushroom-type manager. Since the mushroom-type management behavior does not give importance to the employee, the employees feel excluded.

\section{Organizational Charlatan}

Charlatan in the dictionary of the Turkish Language Institute is defined as "the person who cheats and defrauds others by praising his knowledge and qualities or goods" (TDK, 2014). Thus, the words charlatan and fraud are related to each other and one of the key concepts it holds is that of distrust (Bazarkaya, 2018). Charlatanism can be considered as the claims that employees make regarding having more knowledge and skills than they possess (Fox, 1996). The organizational charlatan scale measures behaviors related to perceived performance levels rather than the actual performance of the employee. The organizational charlatan scale can help the organization to make decisions about human resources by evaluating such employees. These persons try to convince the management that they are performing better than others creating a positive perception about themselves in the minds of the managers (Abraham \& Berline, 2015; Parnell \& Singer, 2001).

The charlatan can fake skills that he does not possess to express his commitment and attachment to the organization and he acts by his written and verbal rules and regulations (Gbadamosi, 2006). Even though charlatanism has been found to have a negative relationship with emotional commitment, organizational commitment, self-evaluation, trust in management, employee participation, goal clarity, and genuine feedback (Gbadamosi, 2006). These persons can deceive even 
the best managers which creates disappointment among colleagues who see the facts. The task of managers is to get to know these people, understand warning signs and control their effects (Parnell \& Singer, 2001).

In another study, it was found that while moral identity affects shame positively, organizational charlatanism behavior does not affect shame significantly (Abraham \& Berline, 2015). Even though mushroom-type management (Tekin \& Birincioğlu, 2017), organizational charlatanism (Gbadamosi, 2006), and organizational loneliness (Ayazlar \& Güzel, 2014; Ertosun \& Erdil, 2012; Jung et al., 2021) are negatively related to organizational commitment; yet, no study investigating the relationship between organizational charlatanism, mushroomtype management, and organizational loneliness has been encountered by the researchers.

\section{Methodology}

This study examines the predictive relationship between mushroom-type management behavior and teachers' organizational loneliness behaviors and teachers' organizational charlatanism behaviors. The research is therefore designed in a relational screening model. Mushroom-type management is an independent variable while organizational loneliness and organizational charlatan behaviors are dependent variables. Regression analysis was carried out to determine the extent to which mushroom type management predicted teachers' organizational loneliness behaviors and teachers' organizational charlatan behaviors. If there is a change between the three variables, what is the degree and direction of it and whether the variables change together are examined (Büyüköztürk, Kılıç Çakmak, Akgün, Karadeniz, Demirel, 2018; Fraenkel, Wallen \& Hyun, 2012; Karasar, 2000).

\section{Research Group}

The research was carried out in the province of Denizli in Turkey. There are 7733 teachers in the population of the study in public schools of which a sample of 464 was taken using the random sampling method. The sample of the study was deemed sufficient as 95\% confidence level, 5\% margin of error (Bartlett et al., 2001). The answers of 464 participants who answered all the questions in the scale were included in the scope of the evaluation. Of the 464 participants, $55.8 \%$ were women and $44.2 \%$ were men and $2.4 \%$ had an associate degree; $84.3 \%$ had received 
undergraduate education; whereas, $13.4 \%$ received postgraduate education. $\%$ of these participants were working at preschool education institutions; $25 \%$ of them were in primary schools; $38.6 \%$ of them were working in secondary schools, and $25.4 \%$ were a part of high schools. The level of schools can be divided according to the age of the children who are inducted in these schools which is as follows:

- Preschool: 36-72 months

- Primary school: 7-10 years

- Secondary school:11-14 years

- High school:11-14 years

\section{Instruments}

\section{Mushroom Type Manager Scale}

The mushroom-type management scale was developed by Birincioğlu and Tekin (2018) and the validity and reliability study of the scale for schools was carried out by Ergün (2020a). The study group of the scale adaptation study is composed of teachers working in Denizli in Turkey. The scale consists of $62.45 \%$ of the total variance and therefore has construct validity. While Cronbach Alpha .95 was found for the overall scale; the correlation between the two halves was found as .90 . Item-total correlations ranged from .26 to .85 for all items, and t-test values were significant. The t-test results of the Mushroom Management Scale for comparison of mean, standard deviation, item-total correlations, and item scores of the lower $27 \%$ and upper $27 \%$ groups support the discrimination of the scale. Thus, the scale was adapted to Turkish as 19 items and one dimension (Ergün, 2020a).

\section{Loneliness Scale}

The UCLA loneliness scale was first developed in 1978 by Russell et al., (1978) and was revised by Russell et al., (1980) which lead to the development of the third version by Russell (1996). The UCLA loneliness scale (3), by Russell (1996) and adapted to Turkish by Ergün (2020b) was used in this study. The study group of the scale adaptation study is composed of teachers working in Denizli in Turkey. The scale was performed on 207 teachers during the 2019-2020 academic year for exploratory factor analysis. The Kaiser-MeyerOlkin $(\mathrm{KMO}=.96)$ test and Bartlett's sphericity test $\left(\mathrm{X}^{2}=3317,441, \mathrm{Sd}=190, \mathrm{P}<.01\right)$ suggested that the 
obtained data was appropriate for factor analysis. As a result of the explanatory factor analysis was found to be the variance explained by the first factor $59.99 \%$, the variance explained by the second factor $6.13 \%$, and the variance explanation ratio of these two factors $66 \%$. As a result of the exploratory factor analysis, it can be said that the scale has construct validity. Factor analysis results were also given in two dimensions. These are individuity and unity dimensions. Since loneliness was measured in the scale, the items in the unity dimension were reversed and included in the analysis. Therefore, it can be said that the person who scores higher than the scale is lonelier. The Cronbach Alpha Coefficient was found to be .96 for the whole scale. The internal consistency coefficient for the first sub-dimension 'togetherness' was .94 , for the second subdimension 'unity' was .93. These findings show that the internal consistency of all of the sub-dimensions of the scale was high. With the semi-test reliability method, which is one of the internal reliability coefficient methods of the scale, the scale is divided into two halves. The relationship between the measurements obtained from the two halves was calculated by Pearson productmoment correlation coefficient. The correlation coefficient between the two halves was established as $\mathrm{r}=.90(\mathrm{p}=.000)$. Item-total correlations ranged from .55 to .83 for all items, and t-test values were significant. Given these findings, it can be said that the reliability coefficient of the scale is sufficient. The t-test results of the Scale for comparison of mean, standard deviation, item-total correlations, and item scores of the lower $27 \%$ and upper $27 \%$ groups support the discrimination of the scale. Thus, the scale was adapted to Turkish as 20 items and two-dimension (Ergün, 2020b).

\section{Organizational Charlatan Scale}

In this study, Organizational Charlatan Scale, which was developed by Parnell and Singer, (2001) was used and adapted to Turkish by the researcher. The study group of the scale adaptation study is composed of teachers working in Denizli in Turkey. The scale was performed on 105 teachers during the 2019-2020 academic year for exploratory factor analysis. The Kaiser-Meyer Olkin $(\mathrm{KMO}=.85)$ test and Bartlett's sphericity test $\left(\mathrm{X}^{2}=654,536 ; \mathrm{Sd}=36, \mathrm{P}<.01\right)$ suggested that the obtained data was appropriate for factor analysis. The scale explains 56,12\% of the total variance. The Cronbach Alpha Coefficient was found to be .89 for the whole scale. With the semi-test reliability method, which is one of the internal reliability coefficient methods of the scale, the scale is divided into two halves. The relationship 
between the measurements obtained from the two halves was calculated by Pearson product-moment correlation coefficient. The correlation coefficient between the two halves was established as $r=.89(p=.000)$. Item-total correlations ranged from .26 to .79 for all items, and t-test values were significant. After exploratory factor analysis, a two-dimensional structure emerged. The t-test results of the Scale for comparison of mean, standard deviation, item-total correlations, and item scores of the lower $27 \%$ and upper $27 \%$ groups support the discrimination of the scale. Thus, the scale was adapted to Turkish as 9 items and one dimension (Ergün, 2021).

\section{Data Collection Procedures}

The research data were collected in Denizli in Turkey in January and February 2020. Before starting the data collection process, permission was requested from the Denizli Provincial Directorate of National Education to apply the scales in schools in Denizli, and the permission for the research with its official writing dated 16.10.2019 and numbered 20163394 was given. The data were collected with the help of online forms. Since the data were collected with the help of an electronic form, it was not possible for the participants to be forced to fill in the scale, or be affected by the researcher.

\section{Data Analysis}

Regression analysis was carried out to determine the extent to which mushroom type management predicted teachers' organizational loneliness behaviors and teachers' organizational charlatan behaviors. In this context, first, the assumptions of the regression analysis were tested. Accordingly, extreme value analysis was carried out at the initial stage. In determining the extreme values, Mahalanobis distances were calculated and it was observed that these values ranged between .00 and 16.75 . When the P-value is accepted as .01, the values that we will accept as the extreme value are 6.63. Therefore, 9 scale data are not included in the analysis (Can, 2018).

The suitability of the research data to the normal distribution was checked according to the skewness and kurtosis coefficient. It was determined that these coefficients were between +2 and -2 in all variables. For the union dimension, was found as the skewness .79 and the kurtosis coefficient was 1.51; for the individuity 
is the dimension, the skewness .88 and the kurtosis coefficient was 1.26 ; for the loneliness scale, the skewness .79 and the kurtosis coefficient was 1.06; for the charlatan scale, the skewness .35 and the kurtosis coefficient was .65; for the mushroom type management scale, the skewness .78 and the kurtosis coefficient was 1.26. According to the mentioned values; It can be said that the research data show normal distribution (Bayram, 2010; Karagöz, 2016; Kunnan, 1998).

Another assumption required for the regression analysis is that there is Multico linearity. Pearson's correlation coefficients between independent variables were investigated to determine whether there were multiple links between variables. It was determined that the correlation coefficients of the variables varied between .21 and .47 according to the total score. According to Büyüköztürk (2012), it is assumed that there may be multiple connections for correlation values above .80. Therefore, it can be said that there are no multiple connections between the variables. VIF values were examined to see if there is multiple linear connections between the data. These values were calculated to be between 1.11 and 2.49, and all VIF values were found to be less than the problematic critical value of 10 (Kleinbaum et al., 1988: as cited in Gujarati \& Porter, 2009; Chatterjee \& Price, 1991: as cited in; Stine, 1995, s.54). It is calculated with the formula VIF=1/ (1- r232). If we write the VIF value as 10 , the value of r23 is about 0.94 . When the r23 value is 1 in the formula, the VIF value is expressed as infinite (Gujarati \& Porter, 2009, s.328). As can be understood from the formula, it can be said that the problem area is approached as the VIF value exceeds 10 . In this context, it can be said that there is no multiple connection problem between variables.

\section{Findings}

This study aims to examine the prediction of the mushroom-type management approach on the loneliness levels of the employees and organizational charlatan behaviors. The first question for which an answer is sought in the research was 'does mushroom-type management behavior predict teachers' organizational loneliness?'. Regression analysis was performed for this purpose. The results of the regression analysis of the mushroom-type manager behavior predicting the organizational charlatanism behavior are presented in Table 1. 
Ergun

\section{Table 1}

Regression Analysis Results Regarding Prediction of Organizational Charlatanism

\begin{tabular}{|c|c|c|c|c|c|c|}
\hline Variable Name & B & Std. error & $\beta$ & $\mathbf{t}$ & $\mathbf{P}$ & $\mathbf{R 2}$ \\
\hline Constant & 18.64 & .915 & \multirow{2}{*}{.21} & 20.37 & \multirow{2}{*}{0.000} & \multirow{2}{*}{.048} \\
\hline Mushroom Type Management & .098 & .021 & & 4.77 & & \\
\hline
\end{tabular}

The regression results between the predictive variable mushroom type management behavior and the predicted variable organizational charlatan behavior are shown in Table 1. According to the above results, the positive $(+)$ direction of Beta value which mushroom type management behavior affects the organizational charlatan behavior indicates that there is a direct relationship between these two variables; it can be said that increasing mushroom type management behavior positively affects the organizational charlatan behavior. Also, it is seen that there is a significantly low level $(\mathrm{r}=.048)$ significant relationship between mushroom-type management and organizational charlatan behaviors. According to the regression analysis; the regression equation for predicting organizational charlatan can be given as "Y $=18.640+0.098 \times$ (mushroom type management) +.021 ". When Mushroom Type Management increases one unit, organizational Charlatanism increases .098 units. This value is realized with .021 error. The 18,640-unit values of organizational charlatanism occur without mushroom-type management. The mushroom-type management included in the model explains about $5 \%$ of the total variance related to the organizational charlatan behavior, which is the dependent variable. This indicates that the $95 \%$ change in organizational charlatan scores can be explained by different variables that are not included in the regression model. When the t-test results related to the significance of the regression coefficients are examined, it is seen that the predictive variable mushroom type management $(\mathrm{t}=4.770, \mathrm{p}<.05)$ is an important predictor in explaining the scores regarding organizational charlatan behavior. Accordingly, considering the positive aspect of the relationship, it can be said that the mushroom-type management positively affected the increase in the points related to organizational charlatan behaviors.

The second question for which an answer is sought in the research is "does mushroom-type management behavior predict teachers' organizational charlatan behaviors?". Regression analysis was performed for this purpose. The results of the regression analysis of the mushroom-type manager behavior predicting the organizational loneliness behavior are presented in Table 2. 


\section{Table 2}

Regression Analysis Results Regarding Prediction of Organizational Loneliness

\begin{tabular}{lcccccc}
\hline Variable Name & B & Std. error & $\boldsymbol{\beta}$ & $\mathbf{t}$ & $\mathbf{P}$ & R2 \\
\hline Constant & 19.09 & 1.78 & \multirow{2}{*}{.473} & 10.68 & \multirow{2}{*}{0.000} & \multirow{2}{*}{.223} \\
Mushroom Type Management & .459 & .040 & & 11.41 & & \\
\hline
\end{tabular}

The regression results between the predictive variable mushroom type management behavior and the predicted variable organizational loneliness behavior are shown in Table 2. According to the above results, the positive $(+)$ direction of Beta value which mushroom type management behavior affects the organizational Loneliness behavior indicates that there is a direct relationship between these two variables; it can be said that increasing mushroom type management behavior positively affects the organizational Loneliness behavior. Also, it is seen that there is a significant $(\mathrm{r}=.22)$ significant relationship between mushroom-type management and organizational loneliness behaviors. According to the regression analysis; the regression equation for predicting organizational loneliness can be given as "'Y $=19.093+.459 \mathrm{x}$ (mushroom type management) +.040 ". When Mushroom Type Management increases one-unit, organizational loneliness increases .459 units. This value is realized with .040 error. The 19.093-unit values of organizational charlatanism occur without mushroom-type management. The mushroom-type management included in the model explains about $22 \%$ of the total variance related to the organizational loneliness behavior, which is the dependent variable. This indicates that the $78 \%$ change in organizational loneliness scores can be explained by different variables that are not included in the regression model. When the t-test results related to the significance of the regression coefficients are examined, it is seen that the predictive variable mushroom type management $(t=11.417, p<.05)$ is an important predictor in explaining the scores regarding organizational loneliness behavior. Accordingly, considering the positive aspect of the relationship, it can be said that the mushroom-type management positively affected the increase in the points related to organizational loneliness behaviors. 
Ergun

\section{Table 3}

Regression Analysis Results Regarding Prediction of Organizational Unity

\begin{tabular}{lcccccc}
\hline Variable Name & B & Std. Error & $\boldsymbol{\beta}$ & $\mathbf{t}$ & P & R2 \\
\hline Constant & 7.81 & 1.012 & \multirow{2}{*}{. } & 7.719 & \multirow{2}{*}{0.000} & .21 \\
Mushroom Type Management & .254 & .023 & & 11.17 & & \\
\hline
\end{tabular}

The results of the regression analysis of the mushroom-type manager behavior predicting the unity dimension of organizational loneliness behavior are presented in Table 3. According to the regression analysis; The positive $(+)$ direction of Beta value which mushroom type management behavior affects the unity dimension of organizational loneliness behavior indicates that there is a direct relationship between these two variables; it can be said that increasing mushroom type management behavior positively affects the unity dimension of organizational loneliness behavior. The regression equation for predicting unity dimension can be given as "Y $=7.813+.254 \mathrm{x}$ (mushroom type management) + .023 ". When Mushroom Type Management increases one unit, the unity dimension of organizational loneliness behavior increases .254 units. This value is realized with .023 error. The 7.813-unit values of organizational charlatanism occur without mushroom-type management. The mushroom-type management included in the model explains about $21 \%$ of the total variance related to the unity dimension, which is the dependent variable. This indicates that the $79 \%$ change in unity dimension scores can be explained by different variables that are not included in the regression model. When the t-test results related to the significance of the regression coefficients are examined, it is seen that the predictive variable mushroom type management $(\mathrm{t}=11.179, \mathrm{p}<.05)$ is an important predictor in explaining the scores regarding the unity dimension. Accordingly, considering the positive aspect of the relationship, it can be said that the mushroom-type management positively affected the increase in the points related to the unity dimension. The results of the regression analysis of the mushroom-type manager behavior predicting the individuity dimension of organizational loneliness behavior are presented in Table 4.

\section{Table 4}

Regression Analysis Results Regarding Prediction of Organizational Individuity

\begin{tabular}{lcccccc}
\hline Variable Name & B & Std. error & $\boldsymbol{\beta}$ & $\mathbf{t}$ & $\mathbf{P}$ & R2 \\
\hline Constant & 11.28 & .926 & \multirow{2}{*}{.419} & 12.18 & \multirow{2}{*}{0.000} & .17 \\
Mushroom Type Management & .204 & .021 & & 9.81 & & \\
\hline
\end{tabular}


The regression results between the predictive variable mushroom type management behavior and the predicted variable individuity dimension are shown in Table 4. According to the above results, the positive $(+)$ direction of Beta value which mushroom type management behavior affects the individuity dimension of organizational loneliness behavior indicates that there is a direct relationship between these two variables; it can be said that increasing mushroom type management behavior positively affects the individuity dimension of organizational loneliness behavior. Also, it is seen that there is a significant $(\mathrm{r}=.17)$ significant relationship between mushroom-type management and individuity dimension. According to the regression analysis; the regression equation for predicting individuity is dimension can be given as "Y $=11.280+.204 x$ (mushroom type management) +.021 ". When Mushroom Type Management increases one unit, the individuity dimension of organizational loneliness behavior increases .204 units. This value is realized with .021 error. The 11.280-unit values of organizational charlatanism occur without mushroom-type management. The mushroom-type management included in the model explains about $17 \%$ of the total variance related to the individuity dimension, which is the dependent variable. This indicates that the $83 \%$ change in individuity dimension scores can be explained by different variables that are not included in the regression model. When the t-test results related to the significance of the regression coefficients are examined, it is seen that the predictive variable mushroom type management $(\mathrm{t}=9.810, \mathrm{p}<.05)$ is an important predictor in explaining the scores regarding the individuity dimension. Accordingly, considering the positive aspect of the relationship, it can be said that the mushroom-type management positively affected the increase in the points related to the individuity dimension.

\section{Discussion}

This study investigated the predictive relationship between mushroom-type manager behavior with organizational charlatan and organizational loneliness. This research played an important role in eliminating the deficiency in the literature as the researcher could not find any study investigating the relationship between these variables.

The first finding of the study is that the mushroom-type management behavior significantly predicted the organizational charlatan behavior at a positive low level ( $\mathrm{r}$ $=.048$ ). In other words, this finding indicates that the $95 \%$ change in organizational charlatan scores can be explained by different variables that are not included in the 
regression model. In previous studies, continuing emotional commitment and work commitments were found among the determinants of charlatan behavior. Charlatan is positively affected by continuing commitment and business performance and negatively affected by emotional commitment (Gbadamosi, 2006). The reasons for organizational charlatan behavior can be found by investigating the relationships with different variables

Mushroom-type management positively affects organizational charlatanism. School principals may not want to make any statements to teachers; however, the school principal can make instructions to meet the demands of the environment or superiors or to achieve school goals. The school principal need not ask the opinions of teachers and may choose to decide without their advice. The teachers who want to stand out shows organizational charlatanism by portraying themselves better than what he/she is, such that the management perceives his/her performance to be better than that of others. A teacher who shows organizational charlatanism behaviors can go up in hierarchical ladder with less performance. However, this situation can be disappointing for the employees who cannot highlight their real performance (Parnell \& Singer, 2001). Organizational charlatan is one of the obstacles to effective and efficient use of human resources of an organization. Also, organizational charlatan is predicted by continuing commitment, emotional commitment, work performance, and mushroom-type management (Gbadamosi, 2006); however, other predictors of organizational charlatanism should also be investigated, since there is still a significant portion that cannot be predicted.

Another finding in the research is that mushroom-type management behavior significantly predicts organizational loneliness behavior in a positive and low level $(\mathrm{r}=.22)$. This hypothesis has been accepted that Mushroom-type management behavior predicts teachers' organizational loneliness. Mushroomtype management, which has the behavior of leaving employees in the dark like a mushroom, and directing them to the target, without any explanation to employees (Tekin \& Birincioğlu, 2017), can push teachers to loneliness at school. For instance, if a school principal wants to win parents' hearts and influence them; the principal may have to use teachers for this purpose. In such a situation, the school principal may not want to inform the teachers but may want to direct them towards certain activities. Without clearly understanding the reasons for the instructions given, there is a fear that a teacher may lose his professional esteem in front of the parents. 
In this case, the teacher can feel alone at school. A teacher who does not share and communicate with his/her colleagues at school may not be expected to be very useful for the school. The value added by the teacher who does not act to realize the general goals of the school may be negative. Mushroom-type management can negatively affect the performance, motivation levels, loyalty, intention to leave the organization, trust in the institutions, power poisoning can occur in management (Kılıç, 2015; Tekin \& Birincioğlu, 2017). Loneliness at work positively affects the intention to quit (Demirbaş \& Haşit, 2016).

Organizational charlatanism and organizational loneliness can negatively affect the achievement of school goals. The principal can move away from the mushroom management approach by measuring the process and sharing with employees, organizing meetings, and informing them (Kahya \& Ceylan, 2019; Miller, 2016). For this reason, the mushroom-type management behaviors should be used when necessary and to adopt a more participatory and transparent management approach. The principal, who wants to increase the authority of the teaching profession, should avoid mushroom-type management behavior in order not to push his/her teacher towards charlatanism or loneliness. The school principal, who wants to increase his authority and popularity, may prefer the mushroomtype management approach at the expense of pushing his teacher to loneliness and charlatanism.

\section{Conclusion and Recommendations}

If the school principal engages in mushroom-type management behavior, it may cause the employee to demonstrate organizational charlatan behavior or loneliness. In both cases, the desired efficiency will not be achieved. Organizational charlatan and organization loneliness are obstacles to the effective and efficient use of human resources of the organization. For this reason, it would be appropriate to use in situations mushroom type management, which is one of the predictors of organizational charlatans, when needed, and to adopt a more transparent and participatory management style.

There is no study investigating the relationship between these variables. Also, studies examining the relationship of these variables with other variables are limited. For this reason, difficulties have been experienced in establishing relationships with past research 
Not informing teachers about their school work will mean asking them to proceed in the dark. This situation may cause teachers to act more cautiously. For this reason, transparent management in schools with teachers will be effective in terms of teacher productivity. There may be different independent variables affecting the variables of organizational loneliness, and organizational charlatan. In this research, mushroom-type management was taken as the independent variable. This research is limited to kindergarten, basic education, and high school formal education institutions. Studies should be repeated with different independent variables affecting the variables of organizational loneliness and organizational charlatan. Different studies should be conducted for higher education institutions.

\section{References}

Abraham, J. \& Berline, R. P. N. (2015). An investigation on organizational charlatan behaviour and moral identity as predictors of shame: Importance for education. Journal of Education and Learning, 9(2),135-144. https:// doi.org/10.11591/edulearn.v9i2.1535.

Ayazlar, G. \& Güzel, B. (2014). The effect of loneliness in the workplace on organizational commitment. Procedia-Social and Behavioral Sciences, 131,319-325. https://doi.org/10.1016/j.sbspro.2014.04.124.

Bartlett, J. E., Kotrlik, J. W. \& Higgins, C. C. (2001). Organizational research: Determining appropriate sample size in survey research. Information Technology, Learning, and Performance Journal, 19(1),43-50.

Bayram, N. (2010). Yapısal eşitlik modellemesine giriş amos uygulamaları. Ezgi Kitapevi.

Bazarkaya, O. K. (2018). Charlatan traveller and migration literature: A reading with the conflict model. Migration Journal, 5(2),175-184.

Birincioğlu, N. \& Tekin, E. (2018). A study on developing the mushroom management scale. Business and Economics Research Journal, 9(1),169185. https://doi.org/ 10.20409/berj.2018.98

Büyüköztürk, Ş. (2012). Sosyal bilimler için veri analizi el kitabı. Pegem Akademi. Büyüköztürk, Ş., Kılıç Çakmak, E., Akgün, Ö. E., Karadeniz, Ş. \& Demirel, F. (2018). Ĕgitimde bilimsel araştırma yöntemleri. Pegem Akademi

Can, A. (2018). SPSS ile bilimsel araştırma sürecinde nicel veri analizi. Pegem Akademi.

Çetin A. \& Alacalar, A. (2016). The role of personality traits, perceived organizational and social support in predicting loneliness in the workplace. International 
Journal of Management Economics and Business, 12(27),193-216. https:// doi.org/ 10.17130/10.17130/ijmeb.2016.12.27.968.

Demirbaş, B. \& Haşit, G. (2016). Loneliness at workplace and its effect on the intention to leave: An application on the academicians. Anadolu Universty Journal of Social Sciences, 16(1),137-158.

Duyan, V., Çamur Duyan, G., Gökçearslan Çifçi, E., Sevin, Ç., Erbay, E. \& İkizoğlu, M. (2008). An examination of variables affecting state of loneliness in high school students. Education and Science, 33(150), 28-41.

Ergün, H. (2020a). Mushroom type management scale. 7th International Eurasian Educational Research Congress, 10-13 September Eskişehir, Turkey.

Ergün, H. (2020b). Turkish adaptation of the loneliness scale for schools. Gümüşhane University Journal of Social Sciences Institute, 11(2), 289-300.

Ergün, H. (2020c). The effect of school transparency on attitude towards supervision. International Journal of Contemporary Educational Research, 7(1), 114126. https://doi.org/10.33200/ ijcer.652497.

Ergün, H. (2021). Örgütsel şarlatanlık ölçeği Türkçe uyarlama çalışması. Academia Journal of Educational Research, 6(1), 93-102.

Ertosun, Ö. G. \& Erdil, O. (2012). The effects of loneliness on employees' commitment and intention to leave. Procedia-Social and Behavioral Sciences, 41, 469-476. https://doi.org/10.1016/j.sbspro.2012.04.057

Fox, R. E. (1996). Charlatanism, scientism, and psychology's social contract. American Psychological Association, 51(8),777-784.

Fraenkel, J. R., Wallen, N. E. \& Hyun, H. H. (2012). How to design and evaluate research in education, McGraw-Hill.

Gbadamosi, G. (2006). Predictors and correlates of charlatan behaviour in a non-western context. Journal of Global Business and Technology, 2(1), 23-32.

Gujarati, D. N., \& Porter, D.C. (2009). Basic econometrics. McGraw-Hill.

Jung, H.S., Song, M.K. \& Yoon, H.H. (2021. The effects of workplace loneliness on work engagement and organizational commitment: Moderating roles of leader-member exchange and coworker exchange. Sustainability, 13(948), 1-14. https://doi. org/10.3390/su 13020948

Kahya, V. \& Ceylan, E. (2019). A new approach to increase business performance: Mushroom management. Journal of Social and Humanities Sciences Research, 6(45), 3773-3781. http://dx.doi.org/10.26450/jshsr.1586

Karagöz, Y. (2016). SPSS ve AMOS 23 uygulamali istatistiksel analizler. Nobel Yayınc1l1k. Karasar, N. (2000). Bilimsel araştırma yöntemi. Nobel Yayın Dağıtım. 
Kayıkçı, K. \& Özyıldırım, G. (2019). Loneliness of supervisors: Its causes and their coping way. Journal of Qualitative Research in Education, 7(4), 1500-1524. https://doi. org/10.14689/issn.2148-2624.1.7c.4s.9m.

Kilıç, T. \& Olgun, H. (2017). Mushroom management approach. Journal of Organizational Behavior Research, 2(2), 106-113.

Kilıç, T., (2015). Mushroom management theory; Sample of health sector. Electronic Business Journal, 14(11),474-480.

Kunnan, A.J. (1998). An introduction to structural equation modelling for language assessment research. Language Testing, 15(3),295-332. https://doi.org/10.1177/ 026553229801500302

Miller, B. (2016, January 6). Stop treating your employees like mushrooms. Retrieved from https://www.entrepreneur.com/article/274279.

Özdemir Y. \& İlhan T. (2012). Self-construal, attachment and loneliness an investigation on university students. Gaziosmanpaşa University Social Sciences Research Journal, 7(1), 157-180.

Özen, Ü. \& Korukçu Sarıcı, M. B. (2010). The effect of loneliness and virtual conversation on sharing loneliness: A study among university students. Journal of Economics and Administrative Sciences, 23(4),15-25

Parnell, J. A. \& Singer, M. G. (2001). Developing an instrument to measure false performance. The Journal of Management Development, 20(5), 441-455. https:// doi.org/ 10.1108/02621710110395426.

Rokach, A. (2014). Leadership and loneliness. International Journal of Leadership and Change, 2(1), 48-59.

Rokach, A., Orzeck, T. \& Neto, F. (2004). Coping with loneliness in old age: a crosscultural comparison. Current Psychology, 23(2), 124-137. https://doi.org/ 10.1007/ BF02903073.

Russell, D. (1996). UCLA loneliness scale (version 3): Reliability, validity, and factor structure. Journal of Personality Assessment, 66(1), 20-40. https://doi.org/ 10.1207/s15327752jpa6601_2.

Russell, D., Peplau, L. A. \& Ferguson, M. L. (1978). Developing a measure of loneliness. Journal of Personality Assessment, 42, 290-294. https://doi.org/10.1207/ s15327752jpa4203_11.

Russell, D., Peplau, L.A. \& Cutrona, C.E. (1980). The revised UCLA loneliness scale: Concurrent and discriminant validity evidence. Journal of Personality and Social Psychology, 39, 472-480. https://doi.org/ 10.1037//0022-3514.39.3.472.

Stine, R. A. (1995). Graphical interpretation of variance inflation factors. The American 
Statistician, 49(1), 53-56.

TDK (2014). Türkçe Sözlük. Ankara: Türk Dil Kurumu Yayını.

Tekin, E. \& Birincioğlu, N. (2017). Mushroom management in the information age's universities. International Journal of Academic Value Studies, 3(14), 22-29. https://doi.org/10.23929/javs.508.

Wright, S. L. (2012). Is it lonely at the top? An empirical study of managers' and nonmanagers' loneliness in organizations. The Journal of Psychology: Interdisciplinary and Applied, 146 (1-2), 47-60. https://doi.org/ 10.1080/00223980.2011.585187

Yaşar, M. R. (2007). Loneliness. Fırat University Journal of Social Science, 17(1), 237260.

Yıldırım, A., Hacıhasanoğlu Aşılar, R., Karakurt, P, Çapık, C. \& Kasımoğlu, N. (2018). Examination of the relationship among depressive symptom, loneliness and eating attitudes in university students with sociodemographic characteristics. Turkish Journal of Family Medicine and Primary Care, 12(4), 264-274. https://doi.org/ $10.21763 / \mathrm{tj} f \mathrm{mpc} .462906$.

Y1lmaz, E. \& Altınok, V. (2009). Examining the loneliness and the life satisfaction levels of school principals. Educational Administration: Theory and Practice, 15(59), 451-469. 